\title{
DEVELOPMENT OF AUTOMATIC CONVEYOR SYSTEM AT CONSTRUCTION SITES
}

\author{
Hiroshi Nojima, Yoshimi Nakata, Masakazu Kakuyama, \\ Seiichi Shibayama, Wataru Isomura, Taro Okamoto \\ Technical Research Institute \\ Fujita Corporation \\ 74 Ohdana-chou, Kohoku-ku, Yokohama-shi, \\ Kanagawa, 223, Japan
}

\begin{abstract}
This paper describes the development of a prototype of automated conveyance system and the feasibility study carried out at the actual construction site. The system, consisting of highly-intelligent robots ( automatic forklift, automatic wagon, automatic lift, and automatic roller conveyor) functioned harmoniously and autonomously realizing an automatic conveyance of palletized interior materials, etc. The operation of the system is controlled by the information from the bar-code attached to the pallets. The result of the feasibility study showed a conspicuous shortening of working hours, and an alleviation of heavy labors.
\end{abstract}

\section{INTRODUCTION}

Although, at the actual site of construction; the importance of automated conveyance has been recognized for a long time, its implementation has not been realized due to the reasons such as that the shapes of object conveyed are not always the same, that the destination of conveyance varies all the time, that traditional engineering techniques have their own limitations, etc. However, now that various kinds of robots employed in construction are being developed, the development of an automated system related to the conveyance for supplying and discarding materials has become necessary. The problem of how to reduce the present labor-intensive operations represented by manual conveyance is also to be urgently coped with.

Our attentions being directed to the above, we developed a prototype of automated system at site for conveying interior materials and experimented to prove its effect at the actual construction site. In this paper, centering on the concept of the development, its method of control, and that of operation, a summary of the system is introduced.

\section{THE CONCEPT OF THE SYSTEM'S DEVELOPMENT}

\subsection{CONCEPTS}

When developing the conveyance system, the following two points were set as its concepts.

1) Available for a fully automated conveyance in future.

2) Available for its introduction to the actual construction site having substantial effects on the reduction of labor-intensive operations, etc. 


\subsection{MATTERS THAT REQUIRE ATTENTION}

When introducing an automated conveyance system which is frequently used for factory facilities, automated warehouses, etc, the following points are to be noted.

1) The types of object conveyed are various

The number of necessary materials for the construction of a usual building is said to be more than 10,000 and their shapes vary from a tiny material such as a bolt to a huge. one in its weight and length like a concrete curtain wall.

2) The system is not permanent facilities

A conveyance system is, after all, temporary facilities at the time of constructing a building, and is eventually removed.

3) The destination of conveyance varies

The destination of load conveyed varies every moment in accordance with the progress' degree of the work.

4) Difficulty in the standardization of the system

Temporary work for the building to construct is greatly influenced by its shape, execution program for the work and environmental conditions.

5) Cooperation with men

However advanced automation of operation may become, with the current robotic techniques, it is indispensable to cooperate with men.

6) Reliability

Conveyance being the most basic operation, the suspension of operation by breakdown, etc causes a great inconvenience to the whole construction work. Therefore, the system itself should stand repetitive use for long hours, and even if a breakdown occurs at part of the system, it should not disturb the whole operation.

7) Immunity against environment

Within the building being constructed, different from a factory, the conveyance system needs to be immune against poor environmental conditions.

8) Limit of size

Because of the strength of floor and the height of ceiling of the building, there is a limit to the weight and the height of the system to be used.

\subsection{MEASURES}

The points to note mentioned in 2.2 are summarized in the problems inherent to the construction work and these problems including economic ones cannot be solved at a stroke even by the current robotic techniques. Taking this into consideration, we set forth conditions and aims as follows and started the development of the system.

1) Limitation to the objects conveyed

The objects conveyed are limited to the goods which can be palletized or 
containerized, thus planning to standardize the shape of good's base.

2) Limitation to the period when the system can be employed

Taking into consideration the limited condition mentioned in 1) and water resistance of materials used for the manufacture of the facilities, the use of the system is to be at the time when the ceiling and the floor of the building are being finished to a certain degree.

3) Unitization

By unitizing the system, ease of setting up and transfer increases and freedom of the system composition expands.

4) Intelligent system

Proceed to make the system work in an intelligent way and make it the whole system as an aggregate of sub-systems.

5) Use of Automatic Guided Vehicle (AGV)

Expects more flexibility for the change of conveyance route by introducing $\mathrm{AGV}$.

6) Man-machine interface

Use positively a progressive man-machine interface such as graphic user interface, voice synthesizer, etc for the purpose of an improvement in efficiency and safety, so that even a person without professional knowledge can easily operate the system.

\section{THE COMPOSITION OF THE SYSTEM}

\subsection{Hardware}

\subsubsection{Horizontal direction conveyance system}

1) AGV

An Automatic Guided Vehicle (AGV) has a distinguished feature that it does not require any special facilities except a guide line along the conveyance route, different from other conveyance facilities like conveyor line, etc. Some of other kinds mounting a sophisticated intelligent function, are able to perform complex actions. As for the navigation methods, there are electromagnetic method to pass loop current into the guide line, magnetic method to attach magnetic tape to the floor instead of a guide line, optic method by using reflection tape, etc.

In the basic experiments and the feasibility study made at the site, a forklift type of AGV (automatic forklift) and that of a wagon type (automatic wagon) were used. The navigation method adopted for the former was electromagnetic, the latter, magnetic. (Fig 1, 2)

2) Roller conveyor unit

For the purpose of transferring, temporary storing and short distance traveling of the load, these roller conveyors are used. Conveyors are unitized to cope with various combinations. A summary of each unit is shown below.

a) Driving roller conveyor unit

This is an unit with a power transmission devices, installing driving function inside the rollers. The unit moves two directions, namely, goes forward and backward by the changeover of polarity. 
b) $\mathrm{X}-\mathrm{Y}$ driving roller conveyor unit

This unit has two pairs of crossed driving rollers inside, and the selection of any moving from among going forward, backward, to the right and to the left is available by rising and falling of either of the rollers.

c) Free roller conveyor unit

This unit consists of rollers and lacks driving function. The conveyance of the load is made manually.

d) Free roller conveyor unit for transferring to hand pallet truck This is an unit for transferring the load to a hand pallet truck.

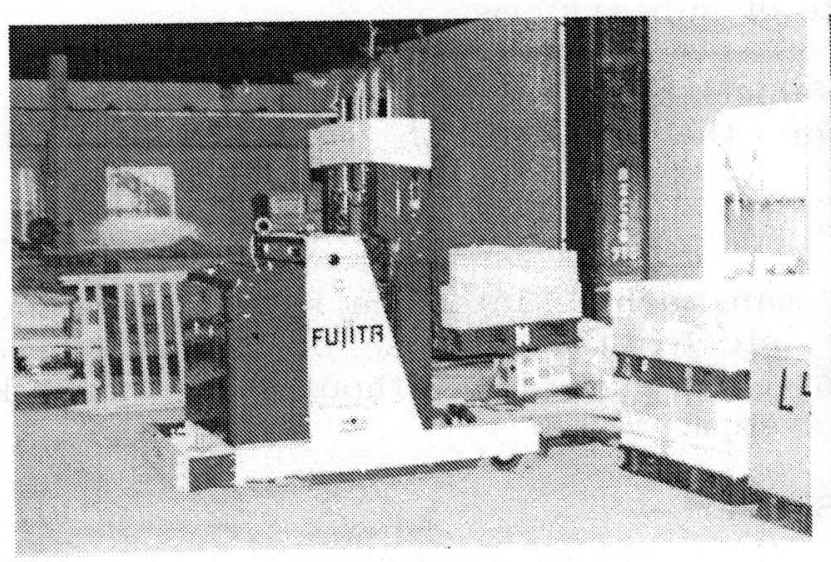

Fig 1: Automatic fork lift

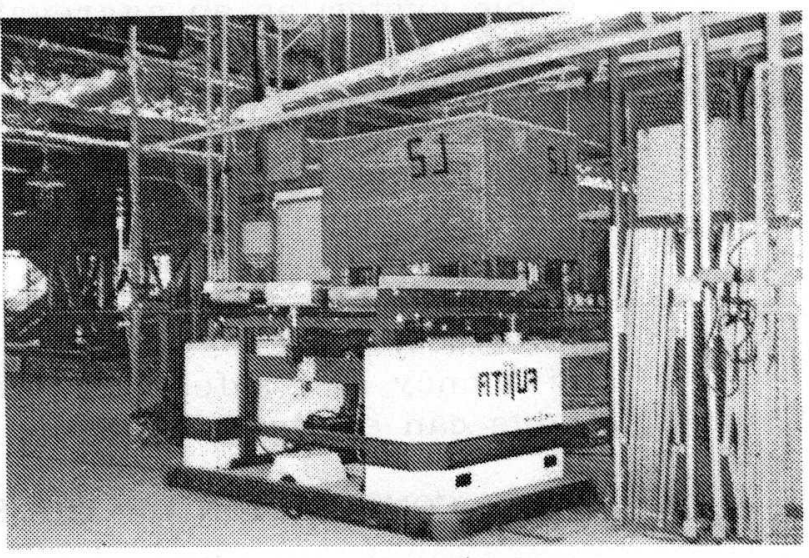

Fig 2 : automatic wagon

\subsubsection{Vertical direction conveyance system}

1). Automatic lift

This is a usual long-span lift made intelligent, equipped with a built in roller conveyor for transferring use, bar-code reader, infrared communication device, etc.

2) Automated gate

Automated gates are installed in front of the lift on each floor, in order to insure safety.

\subsubsection{Storing facilities}

\section{1) Material stockyard}

For sending off and collecting of the load by automatic forklift, a stockyard is needed to store the load temporarily. As the drawing of a guide line is a complex operation, requiring an accuracy of positioning, a stockyard is secured arraying $1.8 \times 0.9 \mathrm{~m}$ board unitized with a built-in guide line.

2) Automatic stock line

This facility is used for transferring and temporarily storing the load. Concretely, it consists of the combination of driving roller conveyor units and $\mathrm{X}-\mathrm{Y}$ driving roller conveyor units, control device and communication device. Basically it takes in and out the load and does the reverse of the action. 


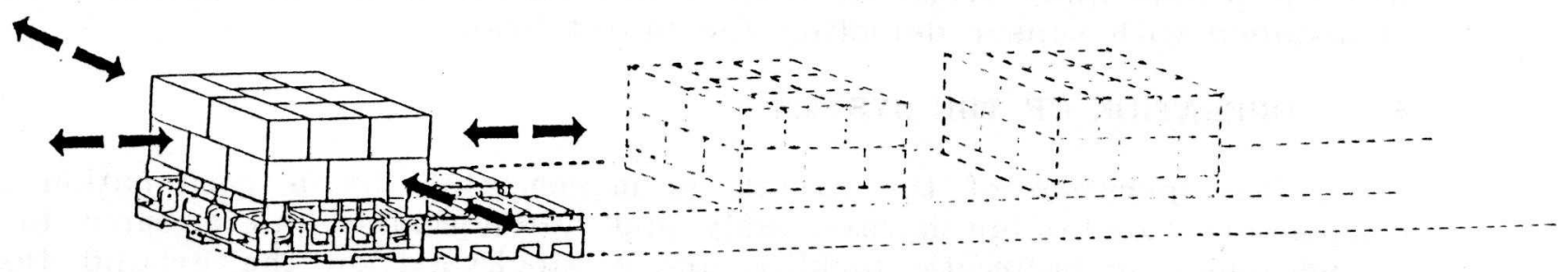

Fig 3 : Example of automatic stock line (transfer direction of load)

\subsection{Software}

\subsubsection{The basic system}

The system is basically composed of the three independent element as software, namely, automatic vehicles, automatic lift and automatic stock lines, and host computer system. The operation control of the system is carried out centering on the automatic lift that mount a bar-code reader. The linkage between the systems is mainly executed by half duplex communication making use of infrared rays.

\subsubsection{Man-machine interface}

1) Graphic user interface

The use of image information has become a remarkably effective means to simplify operation and to summarize information against the tendency favoring more complex and largerscale system. In the developed system, for the operation control of the whole system, liquid crystal display terminal with a touch panel switch, is employed trying an easy operation for the system.

\section{2) Voice synthesizer}

In order to convey the operation information to the workers, voice synthesizer was adopted. The speaker mounted on the lift delivered information about the driving of lift and roller conveyor, opening and shutting the gate, occurrence of errs, etc.

\subsubsection{Operation control}

1) Input of the load's destination

Specification of the load's destination is done by the bar-code label attached to the side of the pallet or by direct input through the user terminal. The utilization of various kinds of information which can be taken in to bar-codes except destination, will be useful for the future control of material.

2) ID code

In order to protect the system's security and to specify the operator, only the input of 4 digit ID code causes the start of the system and the resume from errors.

\subsection{Safety device}

Safety devices are mainly composed of sensor (optical sensor, ultrasonic sensor) used when people approach to the area where machines are in operation, and alarm (action indication light, voice synthesizer, etc) in order 
to keep people away from the area where machines are in operation. And lift is installed with sensor detecting the fall of load.

\section{OPERATION OF THE SYSTEM}

The operation of the system is implemented by a combination of the components functioning harmoniously and autonomously. An example in which we arranged an automatic forklift, and a stockyard on the ground floor, an automatic wagon on the destination floor $(\mathrm{nF})$, with an automatic lift is given as follows. (Fig 4)

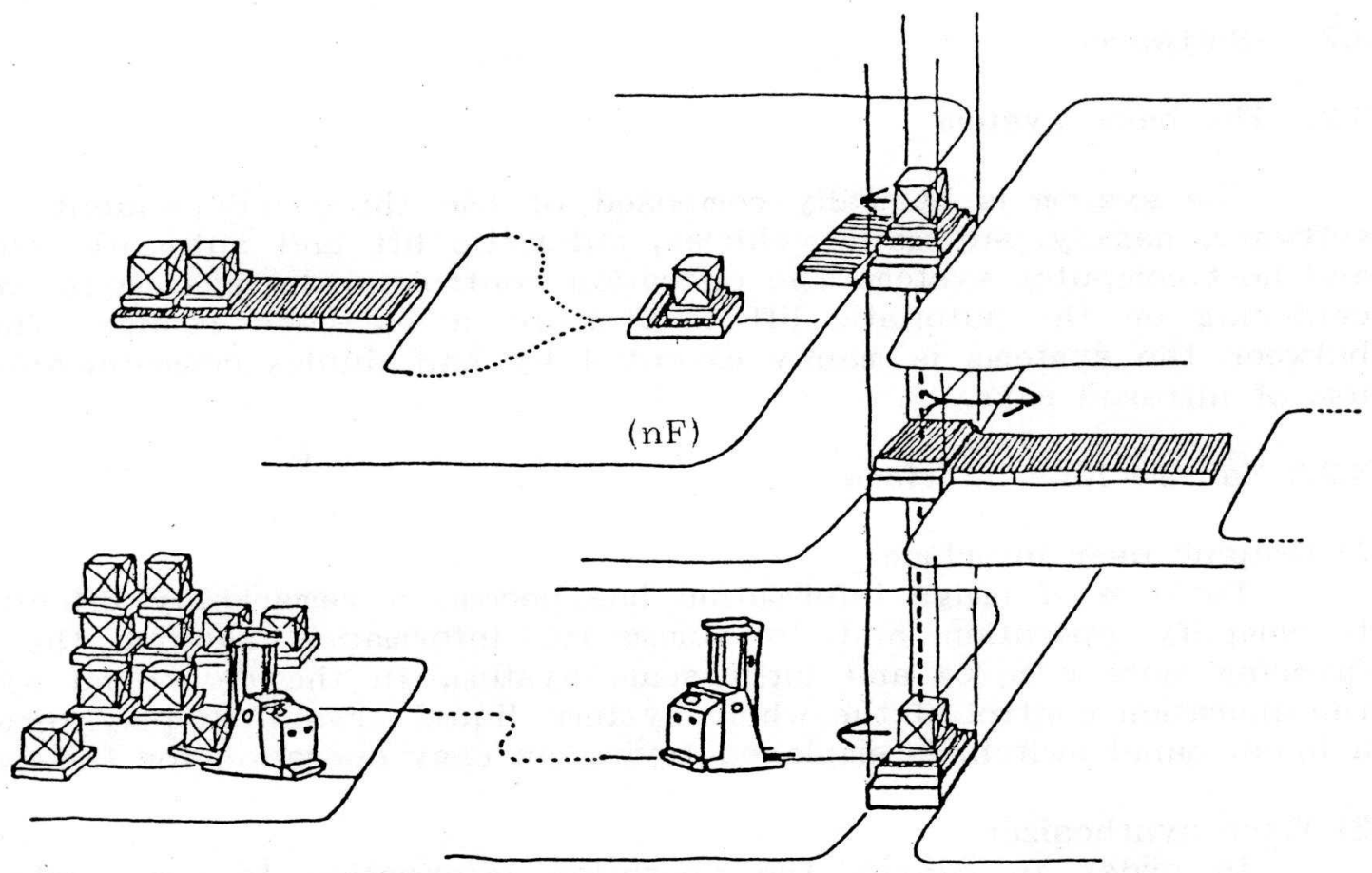

Fig 4 : A plan for transfer of load

1) The palletized materials are conveyed to the site and are placed in the specified location of the stockyard. To the side of the pallet bar-code with destination, etc are stuck.

2) At a starting signal, an automatic forklift runs along the guide line to take out the materials placed in the stockyard.

3) The forklift with an materials again runs to the front of an automatic lift and sends a signal requesting for loading. At a permit signal from the lift, the forklift places the load on the roller conveyor mounted on the lift. Coming back to the waiting spot, the forklift sends a finish signal to the lift. With a confirmation signal, the forklift goes to take the next materials.

4) After sending a confirmation signal, the lift makes sure of the positioning of the materials. If they are beyond the allowable level, the lift corrects their position by operating its roller conveyor. After the confirmation, reading the destination floor on the bar-code, closes the gate and goes up to the floor $(n F)$.

5) On arrival at the floor destined, the lift opens the gate, sends a request 
signal for receiving the load to an automatic stock line. Receiving a permit signal from the stock line, the lift sends out the load operating the roller conveyor. The roller conveyor at the stock line functions synchronizing with the lift's conveyor, receives the load. At a finish signal from the stock line, the lift closes the gate, goes back to the ground floor.

6) The automatic stock line keeps the load temporarily, but at a request signal from the automatic wagon or the automatic lift for sending out the load, it performs the requested operation in the direction of the signal. It is also possible to connect a free roller conveyor unit or a free roller conveyor unit used for a hand pallet truck to the stock line.

7) At the receipt of the load from the automatic stock line in front of the gate, the automatic wagon horizontally conveys the load to another automatic stock line on the destined floor.

As seen from the above, the operation of the system is carried out by the combination of a sequence of 1)-5) and an independent sequence on each floor represented by 7 ). The automatic wagon can also receive the load directly from the lift, the sequence of the system operations is completed. This sequence being reversible, enables the operation of unloading other than loading.

\section{$5 \quad$ FEASIBILITY STUDY}

\subsection{Basic experiments}

In advance of the test applied at the site, the basic experiments were carried on. In these experiments, centering on automatic forklift, automatic lift, automatic wagon, etc, the linkage between the systems viewing from the standpoints of software and hardware the method of operation were examined.

\subsection{Test applied at site}

The feasibility study at the actual site was performed under the following conditions

1) Building

A seven-storied SRC structure at the stage of interior finishing

2) Period

About 2 months during interior finishing work

3) The composition of the system

A combination of automatic forklift, stockyard, automatic lift, automatic stock line, host computer system including user terminal, etc.

An automatic forklift and a stockyard are placed in the stairwell on the ground floor, and automatic stock lines, in front of the gates, on the upper floors (three stories). The automatic stock line consisting of a $X-Y$ driving roller conveyor unit and a driving roller conveyor unit, is connected with 7 free roller conveyor units and that used for transferring to a hand pallet truck. Automatic wagon was not employed according to the process of the construction work. Consequently, horizontal conveyance on the upper floors was tested mainly with a hand pallet truck. In the figures, the main specifications of the components used in the system and a plan for the gland floor are shown. (Fig 5, 6) 


\begin{tabular}{|c|c|c|c|c|}
\hline NAME OF MACHINE & MEASUREMENT $(\mathrm{mm})$ & WEIGHY CAPACITY & VELOCITY & POWER SOURCE \\
\hline automatic forklift & L2300, W1140, H2025 & $1500 \mathrm{~kg}$ & $100 \mathrm{~m} / \mathrm{min}$ & battery $48 \mathrm{~V}$ \\
\hline automatic lift & $L 6550, W 1200$ & $1200 \mathrm{~kg}$ & $10 \mathrm{~m} / \mathrm{min}$ & $A C 200 \mathrm{~V} 3 \phi$ \\
\hline$X-Y$ roller conveyor & $\mathrm{L} 1100, W 900, \mathrm{H} 290$ & $1500 \mathrm{~kg}$ & $4.2 \mathrm{~m} / \mathrm{min}$ & AC $200 \mathrm{~V} 3 \phi$ \\
\hline driving $r$, conveyor & $L 1030, \$ 900, H 270$ & $1500 \mathrm{~kg}$ & $4.2 \mathrm{~m} / \mathrm{min}$ & $\mathrm{AC} 200 \mathrm{~V} 3 \phi$ \\
\hline free roller conveyor & L 1000, W9 30, H $170-270$ & $1500 \mathrm{~kg}$ & & \\
\hline
\end{tabular}

Fig 5: Specifications of the main components



Fig 6 : Plan for the ground floor

4) Operation mode

The operation mode of the system was in the following 4 ways.

a. Fully automatic

a-1 Loading

Convey automatically the load placed in the stockyard on the ground floor to the automatic stock line installed on the destined floor.

a-2 Unloading

Convey automatically the containers for unnecessary materials placed in the stock line on each floor to the stockyard on the ground floor.

b. Automatic

This is the mode excepting the system relevant to automatic forklift. 
Load the materials to be conveyed on the automatic lift, input the destined floor from the terminal, automatically convey the load to the automatic stock line on the destined floor and goes back to the ground floor.

c. Manual

Operate the lift in the usual way. However, the driving roller of the lift and that of the automatic stock lines can be operated manually.

5) Shape of packing and object conveyed

The shape of packing, weight, ete of the material conveyed in an automatic mode were to be, as a principle, as follows.

a. Suitable to be loaded on the specified pallet (L: $1100, \mathrm{~W}: 900 \mathrm{~mm}$ ).

b. Shape of packing is to be under $\mathrm{L}: 1800, \mathrm{~W}: 900, \mathrm{H}: 1300 \mathrm{~mm}$, weight, under $750 \mathrm{~kg}$.

c. The load must not lose balance and must not fall.

As for the goods whose length exceeds that of the pallet $(1100 \mathrm{~mm})$ are to be overhung from the pallet. In a manual mode, the goods with the maximum measurements ( $\mathrm{L}: 3500, \mathrm{~W}: 900, \mathrm{H}: 1400 \mathrm{~mm}$, Weight $1000 \mathrm{~kg}$ ) were treated.

The object conveyed were the materials for finishing interior. Actually, we mainly selected plasterboard as the material to be tried in the experiment as it was large in quantity and in shape, heavy in weight, and its manual conveyance caused an labor-intensive operation.

5.3 Results of the experiment

1) As for the basic adaptability of the system on site, almost satisfactory results were obtained.

2) About $75 \%$ of the experiments with the use of lift were carried out in modes of either fully automatic or automatic.

3) In comparison with the usual manual conveyance, a remarkable effect on the lightening of the labor intensive operation was proved.

As an example, the comparison made among the three modes at the time of conveying plasterboard is shown below.

Object conveyed : 600 pieces of plasterboard $(1800 \times 900 \times 9 \mathrm{~mm})(* 1)$

Conveyance distance : From the ground floor to the $3 \mathrm{rd}$ floor

(including a $20 \mathrm{~m}$ horizontal conveyance)

The time required :
Fully automatic mode
(*3) : 45 minutes
Automatic mode
(*4) : 25 minutes
Manual mode
$(* 5) \quad: 250$ minutes $(* 6)$

(*1) A truckload or 10 piles of 60 pieces' package. When loading a truck, the material is palletized.

(*2) The horizontal conveyance in a mode either fully automatic or automatic on the upper floor was done by hand using a hand pallet truck.

(*3) The time consumed in transfer to the stockyard is not included. 
(*4) The transfer of the load from truck to automatic lift was manually made by forklift.

(*5) With a truck pulled up at the lift, the board was directly transferred to the lift. The conveyance on the upper floor was also done by manually without either roller conveyor or a hand pallet truck.

(*6) Including an intermission during operation.

4) In a system related to the basic operation as this, man-machine interface plays an important role. The one used in this system was received without feeling out of place. A major reason for this may be due to the spread of graphic user terminal employed at banks, etc. The warning alarm sounded by voice synthesizer also brought about a great effect.

\section{CONCLUSION}

1) The lightening of labor-intensive operation was resulted from the effect of automatization at the construction site and at the heart of such innovation lies the importance of means whereby the transfer of the load between conveyance devices is possible. That is, all goes back to "keep the load always in an active state", a fundamental idea for an efficient conveyance.

2) The perfect automatization of load's conveyance is thought to be basically possible by utilizing the developed system. However, among the points to require attention mentioned in 2.2, the problem such as 1), 7), 8), are at present, not yet solved. Especially, standardization including the palletization of the shape of package is needed to tackle further in future.

3) In this system, we tried a very simple collaboration with plural robots. It is regrettable that we still cannot obtain any knowledge about the interaction among machines as seen in the situation in which plural AGV moves about on the same floor. In future, when an increased number of robots are working in the construction site, the interaction among robots and that between men and robots will present very important problems. Among them group control and man-machine interface are thought to be significant research themes for us to take up. 